\title{
Metabolism analysis and eco-environmental impact assessment of two typical cement production systems in Chinese enterprises
}

\author{
Dan $\mathrm{Hu}^{\mathrm{a}}{ }^{\mathrm{a}}$, , Zhen Guo $^{\mathrm{a}}$, Zhen Wang ${ }^{\mathrm{b}}$, Qiang Xiao ${ }^{\mathrm{a}}$ \\ a State Key Lab of Urban \& Regional Ecology, Research Center for Eco-Environmental Sciences, Chinese Academy of Sciences, Beijing 100085, China \\ ${ }^{b}$ School of Environmental Sciences and Engineering, Beijing Forestry University, Beijing, China
}

\section{A R T I C L E I N F O}

\section{Article history:}

Received 28 November 2013

Received in revised form 5 April 2014

Accepted 20 May 2014

Available online 27 May 2014

\section{Keywords:}

Cement production metabolism

Industrial metabolism

Material and energy flows

Use efficiency

Environmental emissions

\begin{abstract}
A B S T R A C T
As one of the primary raw materials in the construction industry, cement production consumes a great deal of resources and has various environmental effects. During the production phase in particular, different procedures play a decisive role in determining the input and output. China has become both the largest producer and the largest consumer of cement worldwide. Together, the two most common production processes in China, the shaft kiln and the NSP (New Suspension Preheater) kiln, account for more than 95\% of total production capacity. Although the proportion of NSP kilns continues to increase each year, shaft kilns are still adopted in numerous small and medium-sized enterprises due to their lower costs and quick yields. During the period of technical transformation and the emergence of continuous environmental issues, it is of great importance to quantify the metabolic processes of typical construction materials, particularly in order to conduct a comparative analysis with different production techniques. However, due to the limited availability of data, relevant studies are rare. In this paper, two typical cement enterprises with different production processes were selected in order to investigate material and energy use as well as pollutant emissions. Metabolic processes were then compared and a use efficiency analysis for different procedural phases was conducted using material flow analysis (MFA). The results are as follows: the shaft kiln requires more raw materials, such as limestone, clay, and coal, per unit product. The efficiency of energy consumption (including electric power consumption and overall energy consumption) is also lower for the shaft kiln than for the NSP kiln. As for environmental emissions, the shaft kiln emits more $\mathrm{SO}_{2}, \mathrm{CO}_{2}, \mathrm{NO}_{\mathrm{X}}$, and dust per unit product than the NSP kiln and has higher eco-environmental impacts.
\end{abstract}

(c) 2014 Elsevier B.V. All rights reserved

\section{Introduction}

The production and consumption of any industrial products require a great deal of material resources and energy, and inevitably discharge pollutants into the environment (Baumann and Tillman, 2004; Graedel et al., 1995). Along with rapid global economic development in recent decades, environment-related impacts of different production processes in industrial systems have been of increasing concern in a variety of different disciplines (Wiedmann et al., 2007).

Frosch presented the concept of "industrial metabolism" in 1989 and identified it is an important aspect of industrial ecological research, referring to the flow processes of material and energy in economic or industrial systems at different local, regional, and global levels (Frosch, 1992; Frosch and Gallopoulos, 1989). By examining the transformation and paths of these fluxes in any industrial system, reasonable ways to improve the use efficiency and reduce consumption of resources and resulting environmental impacts can be found (Ayres, 1989; Erkman, 1997). Based on the definition presented above, relevant research can actually be found dating back to the 1960s, when the terms "urban

\footnotetext{
* Corresponding author. Tel.:+86 106284 9199; fax: +86106294 3807 .

E-mail address: hudan@rcees.ac.cn (D. Hu).
}

metabolism" and "production flow analysis" were first put forward (Burbidge, 1963; Fischer-Kowalski and Hüttler, 1998; Wolman, 1965).

Over the past several decades, significant progress has been made in this field. Numerous studies have targeted particular elements or materials, including cadmium, iron, zinc, copper, lead, mercury, plastics, PVC, and compounds of and phosphorous in industrial or economic systems at national, regional, and urban levels (Forkes, 2007; Guo et al., 2010; Kleijn et al., 2000; Mansson et al., 2009; Michaelis and Jackson, 2000; Spatari et al., 2005; Stigliani et al., 1993; Yang et al., 2015). Several relatively comprehensive studies have focused on the entire processes of material and energy flows in, construction systems, and the industrial sector, among others (Bergsdal et al., 2007; Jorgenson and Rice, 2005; Li et al., 2009). In recent years, the study of material stock has become an important branch of industrial ecology research, as it can contribute to assessing resource appropriation and potential environmental impacts (Gerst and Graedel, 2008; McMillan et al., 2010). Among these studies, various methods have been applied, such as MFA (material flow analysis), LCA (Life Cycle Assessment), Emergy Analysis, Ecological Footprint Analysis, and Input-Occupancy-Output Analysis combined with the state-of-the-art technologies of GIS and remote sensing (Brunner, 2012; Ortiz et al., 2009; Udo de Haes et al., 1997; Ulgiati et al., 1994; Wiedmann and Minx, 2007). These studies have enhanced 
our understanding of the material metabolism of different industrial production systems and of element circulatory processes at different scales.

The production of cement, one of the primary raw materials in the construction industry, generally consumes a great deal of resources and has various environmental effects (Aïtcin, 2000; Madlool et al., 2011). As the production of cement has increased, problems related to associated resources and the environment have increased markedly (WBCSD/ CSI, 2009a). In 2011, annual carbon emissions from the cement production industry accounted for $8 \%$ of global $\mathrm{CO}_{2}$ emissions (Lei et al., 2011; Schneider et al., 2011). China has become both the largest producer and the largest consumer of cement worldwide, with an increasing annual rate of approximately $10 \%$ in total output. In 2012, the total production of cement in China reached up to 2.18 billion tons, accounting for $57 \%$ of global cement production (Salazar and McNutt, 2011). The annual direct physical input in the manufacturing of cement of China accounts for $20 \%$ of the entire input, while the production of 1 ton of cement requires the direct input of 1.6 tons of limestone and clay and $5.5 \mathrm{GJ}$ of energy $\left(1 \mathrm{GJ}=10^{9} \mathrm{~J}\right)$. Meanwhile, total emissions of dust, $\mathrm{CO}_{2}$, and $\mathrm{SO}_{2}$ from the Chinese cement industry account for $27.1 \%, 21.8 \%$, and $4.9 \%$ of national emissions, respectively (Ma et al., 2005). Cement production has recently already become the second largest source of emissions in China, with emitting 0.93 billon tons of $\mathrm{CO}_{2}$ (Xu et al., 2012).

Together, the two most common production processes in the Chinese cement production industry, the shaft kiln and the NSP (New Suspension Preheater) kiln, account for approximately $96.8 \%$ of the total production capacity (Sui, 2009). Although the proportion of NSP kilns continues to increase each year as a newly developed technology in cement production, the shaft kiln is still adopted by numerous small and medium-sized enterprises due to their lower costs and quick yields. As for the production phase, differences in the two production procedures play a decisive role in determining the input and output of material and energy. During the period of technical transformation and the emergence of continuous environmental issues, it is of great importance to quantify the metabolic processes of cement production, particularly in order to conduct a comparative analysis with different production techniques at the enterprise level. Due to the limited availability of data, relevant studies are rare.

In this paper, two typical cement enterprises with different production processes were selected in order to investigate raw material and energy usage and pollution emissions per unit product of cement. By conducting a comparative analysis on the metabolic flow, use efficiency, and environmental impacts associated with shaft kilns and NSP kilns, we seek to explore reasonable ways to increase the use efficiency of resources, reduce pollutant emissions, and promote the transition to a sustainable and circular manufacturing mode for building material enterprises.

\section{Methods}

\subsection{The scope of the study}

The system boundaries of this study include all direct processes associated with cement production. System inputs include raw materials, fuels, electric power, and other necessary materials. Those ultimately flowing out of the system are defined as system outputs, which include products and pollutants, among others. The system stock refers to the storage of materials, usually in a silo, in which intermediate products, such as raw materials, clinkers, and cement products for the next step in production process, remain temporarily. The materials and energy consumed in cement production include: 1) limestone, clay, iron additives, gypsum and mixtures added for cement grinding; 2) coal and electricity that are the main sources of energy consumed and are usually input from external systems in most Chinese cement enterprises (see Fig. 1).

In general, flows of materials and energy proceed continuously throughout the cement production process, although certain interim products are stored in particular production phases. For simplicity's sake, the system stock is not taken into account in this study. The cement production process is generally divided into three phases, namely, the preparative phase yielding raw meal (including grinding), the calcinating phase yielding clinker, and the milling phase yielding cement (see Fig. 2). These three phases constitute the complete cement production process, each with its own input, transformation, and output characteristics, which will be described in greater detail in the following sections.

\subsection{Research methods}

This study adopted the method of material flow analysis (MFA). First, an investigation was conducted to collect basic data, whereupon the direct consumption, pollutant emissions, and dynamic balance of material and energy flows for the enterprise-level cement production system were calculated, and the two cement production procedures (the shaft kiln and the NSP kiln) within two typical enterprises were compared. Flows that have nothing to do with the final product are treated as hidden flows. The analytical framework is presented in Fig. 2.

The entire production process can be divided into three phases in accordance with the information presented in Section 2.1 (also see Fig. 2). In the procedures associated with the shaft kiln, the output of the preparative phase for raw meal consists of raw meal balls mixed with coal powder, commonly known as black raw meal. In the procedures associated with the NSP kiln, the output of the same phase is white raw meal without coal powder. Thereafter, the output of the clinker-calcinating

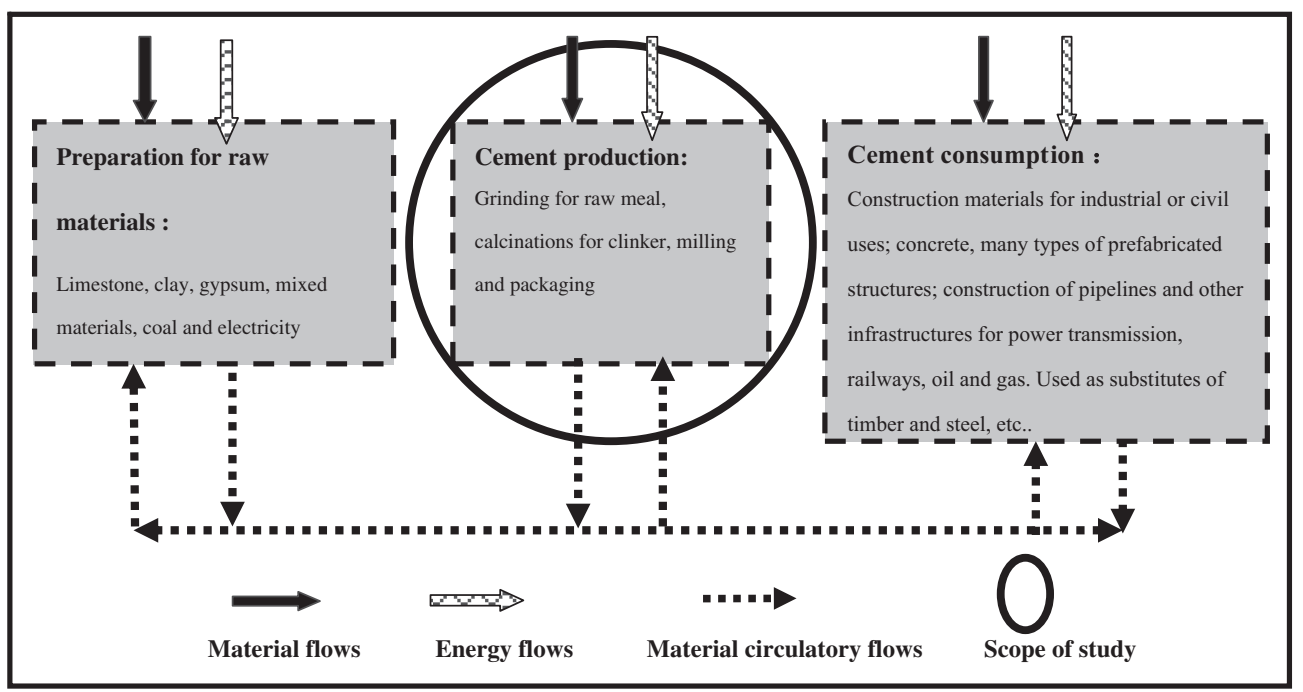

Fig. 1. The analysis scope of cement productive system. 


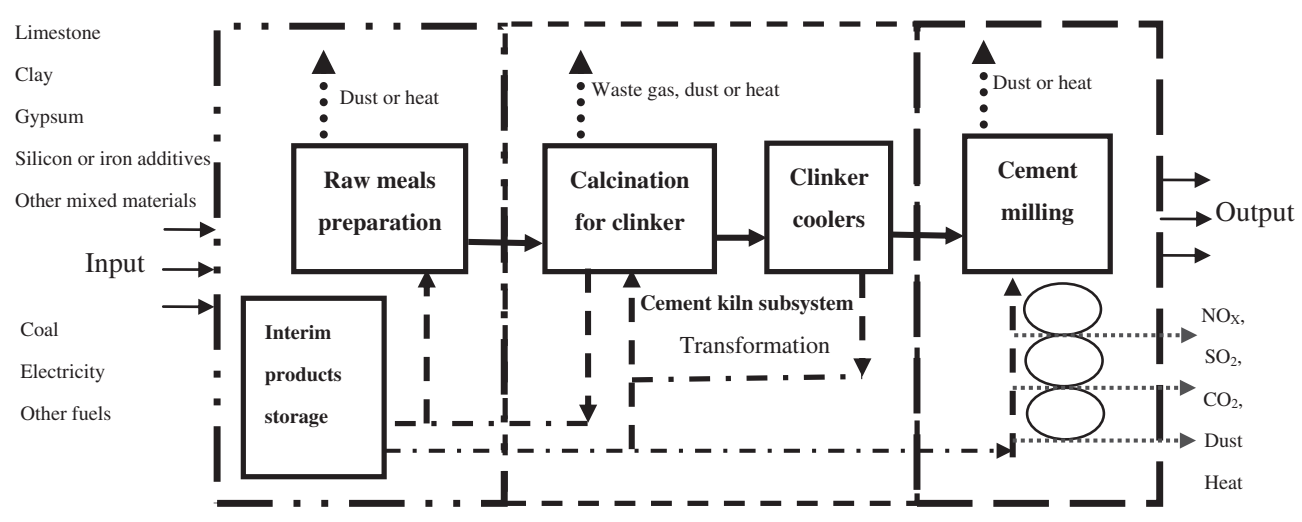

Fig. 2. Diagram of material and energy flows in the cement productive system.

phase in both procedures is clinker, the main semi-finished product of the cement production system. The output of the last milling phase in both procedures is cement, which is also the final product of the cement production system as a whole. As for input, energy is required in each production phase, which results in emissions of particular waste gases, heat, and dust. The clinker-calcinating phase requires a certain amount of air input that can be calculated in accordance with the carbon content of the coal (the average carbon content of $70 \%$ for various types of coals in China was used for this calculation) and the amount of oxygen required for coal combustion (assuming complete combustion). Air and water, the other input materials that flow into the production system, do not participate in the production process and are fixed in the final product; they are thus considered as hidden flows.

The packaging phase was not included in the analysis since it is not necessary to the actual production of cement. In addition, the consumption of material and energy during the packaging phase accounts for less than $3 \%$ of the total consumption. Packaging is thus only a tiny component of cement production systems compared with other phases and can safely be ignored.

\subsection{Enterprise investigation and data collection}

Cement production and environmental emissions data were collected from two typical cement enterprises in Chuzhou City, Anhui Province, where cement production is regarded as pillar industry. The two plants have an average production capacity and equipment, and have a shaft kiln production line and an NSP kiln line, respectively.
The annual outputs amount to 100,000 tons of clinker for the shaft kiln line and 850,000 tons of clinker for the NSP kiln line. The data collected included the main consumption of all kinds of raw materials, including limestone, clay, coal ash, mixed materials, gypsum, and iron additives; energy (coal and electricity); and the overall material and energy flows (input, transformation, storage, and output) in the production processes in these two enterprises.

\subsection{Analytical indicators of cement production metabolism}

According to the dynamic balance of material and energy flows in the cement production system, we can analyze the metabolic characteristics of materials and energy in the cement production system further. Based on the overall status of resource use and the environmental emissions of Chinese cement enterprises, two categories of indicators were established and used to analyze the metabolic behaviors of cement production as descried below (see Table 1).

1) The following indicators are used for analysis at a process level: electricity consumption or heat consumption per unit of intermediate or final product ( $E_{u e}$ or $\left.E_{u h}\right), \mathrm{CO}_{2}$ discharge amount per unit of intermediate or final product $\left(D_{c d}\right)$, dust release amount per unit of intermediate or final product $\left(D_{d t}\right), \mathrm{SO}_{2}$ discharge amount per unit of intermediate or final product $\left(D_{s d}\right), \mathrm{NO}_{\mathrm{X}}$ discharge per unit of intermediate or final product $\left(D_{n x}\right)$, efficiency of output $\left(E_{o}\right)$, and material use efficiency as total input of materials per unit of intermediate or final product $\left(M_{u t}\right)$.

Table 1

Descriptions of proposed indicators for cement production metabolism.

\begin{tabular}{|c|c|c|}
\hline Indicators & Calculating methods & Explanations \\
\hline \multicolumn{3}{|c|}{ Metabolic efficiency of materials or energy } \\
\hline \multicolumn{3}{|c|}{ Energy use efficiency } \\
\hline$E_{\text {ue }}$ & $E_{u e}=T C E / O_{p}\left(E_{u e}\right.$ for electricity $)$ & $T C E$ or $T C H$ is respectively the total used amount of electric \\
\hline$E_{u h}$ & $E_{u h}=T C H / O_{p}\left(E_{u h}\right.$ for heat $)$ & power or heat energy; $O_{p}$ is the total output or products \\
\hline$E_{u t}$ & $E_{u t}=(T C E+T C H)\left(E_{u t}\right.$ for heat for total energy consumption $)$ & within the studied metabolic processes. \\
\hline \multicolumn{3}{|c|}{ Material use efficiency } \\
\hline$M_{u d}$ & $M_{u d}=T D I / T P O\left(M_{u d}\right.$ for direct input of materials per unit product $)$ & TDI is the direct input of various types of production materials; \\
\hline$M_{u t}$ & $M_{u t}=T T I / T P O\left(M_{u d}\right.$ for total input of materials per unit output) & $\begin{array}{l}\text { TPO is the total output of intermediate or final products; TTI is } \\
\text { the total input of various types of production materials. }\end{array}$ \\
\hline \multicolumn{3}{|c|}{ Efficiency of output } \\
\hline$E_{o}$ & $E_{o}=T P O / T D I \times 100 \%$ & $\begin{array}{l}T P O \text { is the total output of intermediate or final products; TDI is } \\
\text { the direct input of various types of production materials. }\end{array}$ \\
\hline \multicolumn{3}{|c|}{ Emissions of environmental wastes } \\
\hline \multicolumn{3}{|c|}{ Coefficient of pollutants' discharges } \\
\hline$D_{c d}$ & $D_{c d}=T D C / T P O$ & $T P O$ is total output of intermediate or final products; TDC, TDS, \\
\hline$D_{s d}$ & $D_{s d}=T D S / T P O$ & $T D N$ or TDD is respectively total discharge amount of $\mathrm{CO}_{2}, \mathrm{SO}_{2}$, \\
\hline$D_{n x}$ & $D_{n x}=T D N / T P O$ & $\mathrm{NO}_{\mathrm{X}}$ or dust for total output of intermediate or final products. \\
\hline$D_{d t}$ & $D_{d t}=T D D / T P O$ & \\
\hline
\end{tabular}

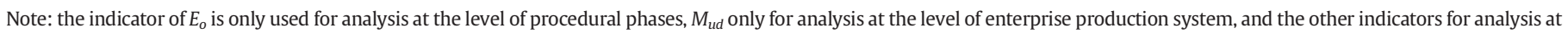
the two levels. 


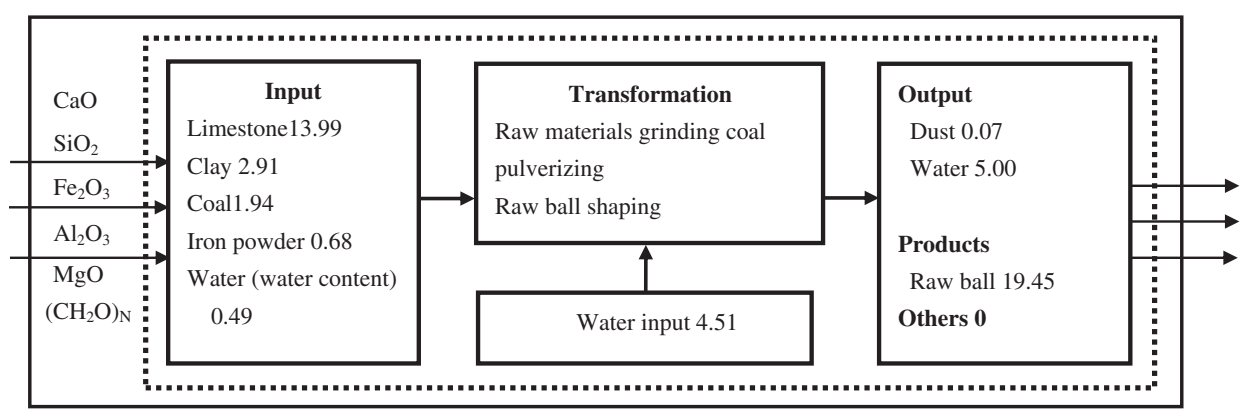

Fig. 3. Metabolic balance diagram in the preparative phase for raw meals for the shaft kiln procedural line (unit: tons/h).

2) The following indicators are used for analysis at an enterprise level for cement production: material use efficiency, including direct input of materials per unit of cement product $\left(M_{u d}\right)$ and total input of materials per unit of cement product $\left(M_{u t}\right)$; and electricity consumption per unit of cement product, overall energy consumption per unit of cement product (total energy consumption), and pollutant release $\left(\mathrm{SO}_{2}, \mathrm{CO}_{2}\right.$, dust, and $\left.\mathrm{NO}_{\mathrm{X}}\right)$ per unit of cement product $\left(D_{c d}, D_{s d}, D_{n x}\right.$, and $D_{d t}$, respectively).

The indicator of use efficiency of total raw materials is defined as the ratio between outputs (intermediate or final products) and the total direct inputs of various types of production materials.

As for the indicators in per unit of cement product, the direct inputs of materials include limestone, clay, coal, iron powder additives, mixed materials, gypsum, and oxygen, but exclude the inputs of water added or contained in the raw materials or energy. The total input of materials consists of the direct input of materials and the input of hidden flows, which includes all amounts of water, and the other components of air, aside from oxygen.

\section{Material metabolic balances in the cement production system}

The two prevailing types of production processes used in Chinese cement enterprises were selected in order to compare the differences in material flows during cement production processes.

\subsection{Material metabolic balance in the shaft kiln procedural line}

The annual output for the cement enterprise with a shaft kiln production system investigated was designed for 100,000 tons of clinker. The overall features of the shaft kiln production line include high energy consumption, limited production capacity, low labor productivity, and a large amount of dust emissions. The dynamic metabolic analysis of the shaft kiln production line is conducted for a unit of time of $1 \mathrm{~h}$ at a normal production level.

\subsubsection{Analysis of material flows in the preparative phase for raw meal}

In the preparative phase for raw meal, the crude raw materials are ground into fine particles of a certain size range that meets the procedural requirements; then, water and other necessary materials are added to form raw balls, the final semi-product of the procedural phase. During this phase, input includes limestone, clay, coal, iron powder, and water contained in the raw materials or added in the procedural line. The phase includes three interior transformative processes: grinding the raw materials, coal pulverization, and the formation of raw balls by adding water to the white ground raw materials. Raw balls are the final product of this phase. The detailed material flows are described quantitatively in Fig. 3. In this phase, the ball products account for the majority of the total output, amounting to up to $79.32 \%$ (not including water). The main emission of pollutants is dust, which accounts for $0.29 \%$ of the total output.

\subsubsection{Analysis of material flows in the calcinating phase for clinker}

In the calcinating phase for clinker, the raw meal (mainly $\mathrm{CaCO}_{3}$ ) is mixed with fuels as coal. Adding air into the kiln for calcinating causes the raw meal to decompose into clinker (mainly $\mathrm{CaO}$ ) at a high temperature. Various pollutants are generated in the process.

The amount of pollutant emissions is greatest during this phase in comparison with the other phases of cement production processes. The major pollutants are waste dust and waste gases, which include carbon dioxide, sulfur dioxide, and nitrogen oxides. The emission of carbon dioxide stems primarily from two sources, the decomposition of limestone as a raw material and the combustion of coal as a fuel. The amount of carbon dioxide emitted makes up a large part of the total output in

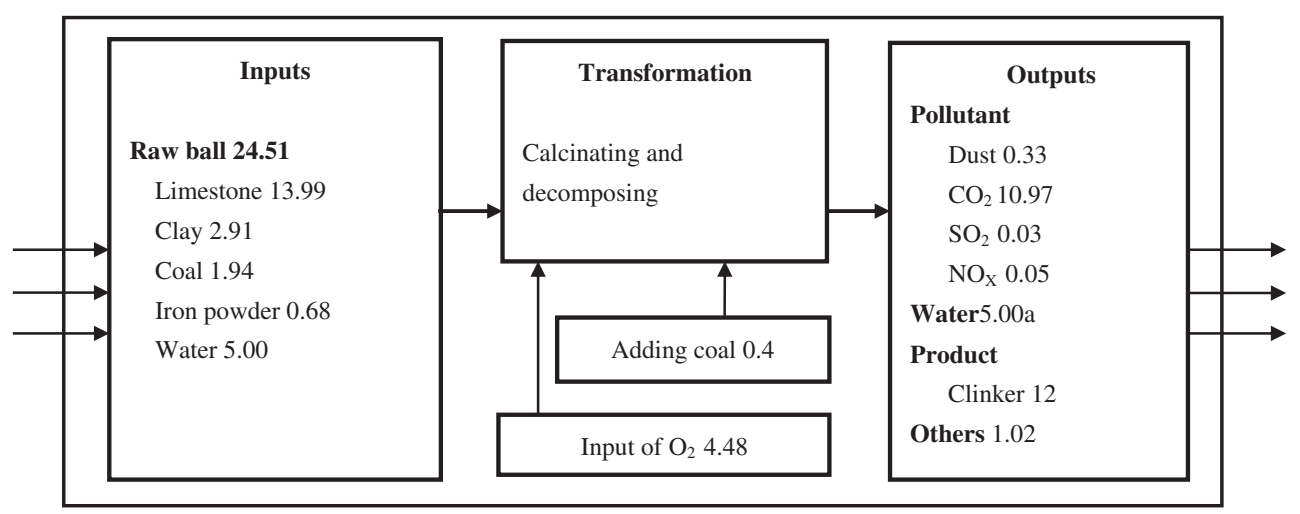

Fig. 4. Metabolic balance diagram in the calcinating phase for clinker for the shaft kiln procedural line (unit: tons/h). 


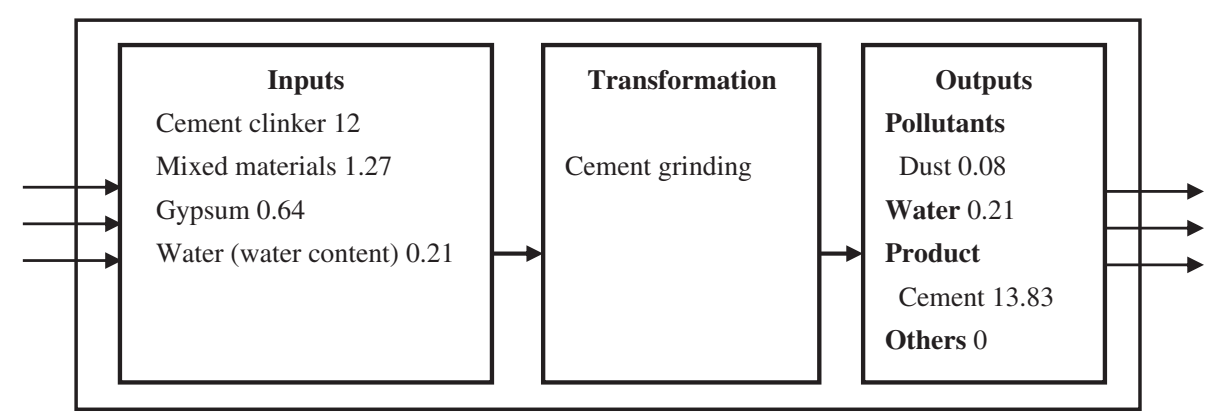

Fig. 5. Metabolic balance diagram in the cement milling phase for the shaft kiln (unit: tons/h).

the phase and reaches 37.34\%. Dust emissions arise from number of different procedural activities, such as crushing, grinding, handling, transporting, and kiln-drying, amounting to $1.11 \%$ of the total output in the phase. The clinker product is the main output in this phase, accounting for $40.83 \%$ of the total output, while other by-products account for $3.46 \%$ (see Fig. 4).

\subsubsection{Analysis of material flows in the cement-milling phase for the shaft kiln}

The clinker from the cement kiln, mixed together with gypsum and other additives, is milled into fine particles of a particular size in the cement milling sub-system, which are a final product of cement. This phase consists entirely of physical processes; no chemical processes are involved, as described and depicted in Fig. 5.

Inputs for this phase include cement clinker, mixed materials, gypsum, and water contained in the input materials; the main pollution emissions are dust and noise. The dust pollution is serious since the production scale of shaft kilns is small and the necessary equipment for dust collection and noise abatement is outdated. The product of cement accounts for $97.97 \%$ of the total output while dust pollutants from this phase account for $0.53 \%$ of the total output.

3.2. Analysis of the material metabolic balance in the cement production system of the NSP kiln

Compared with the shaft kiln, the NSP kiln is a production system of high efficiency, good production continuity, high output, and low overall energy consumption. In addition, with better dust collection and noise elimination equipment, the production system of the NSP kiln can greatly reduce the consumption of resources and pollutant emissions.

\subsubsection{Material metabolic balance in the "continuous baking and grinding" phase (modern rotary kiln)}

The greatest difference between the NSP kiln and shaft kiln lies in the continuity of production. The grinding of raw materials and calcinating for clinker are closely linked as one complete procedural phase in the NSP kiln. In addition, the residual heat from the kiln in the calcinating process is used to dry or bake raw materials in the grinding phase with the addition of coal powder. The metabolic balance diagram in the "continuous baking and grinding" phase is depicted in Fig. 6.

The main output in this phase is clinkers, which account for $51.12 \%$ of the total output; $\mathrm{CO}_{2}$ emissions are relatively large, accounting for $40.88 \%$. Compared with the corresponding phase for the shaft kiln, dust emissions are quite small, accounting for only $0.21 \%$; other byproducts account for $5.31 \%$, a larger percentage than for the shaft kiln.

\subsubsection{Material metabolic balance in the cement-milling phase for the NSP kiln (new style dry kiln)}

In the cement-milling phase for the NSP kiln, clinker, gypsum, and other mixed materials are milled together into particles of a certain size, and the final product as cement is formed. In contrast with the shaft kiln, the clinker in the NSP kiln stems mainly from the "continuous baking and grinding" phase (100 tons/h), with only a very small part originating from the clinker storage of the previous production phase ( 2 tons/h). The total clinker thus amounts to 102 tons/h. Another difference between the shaft kiln and the NSP kiln is that the input in the NSP kiln contains no water.

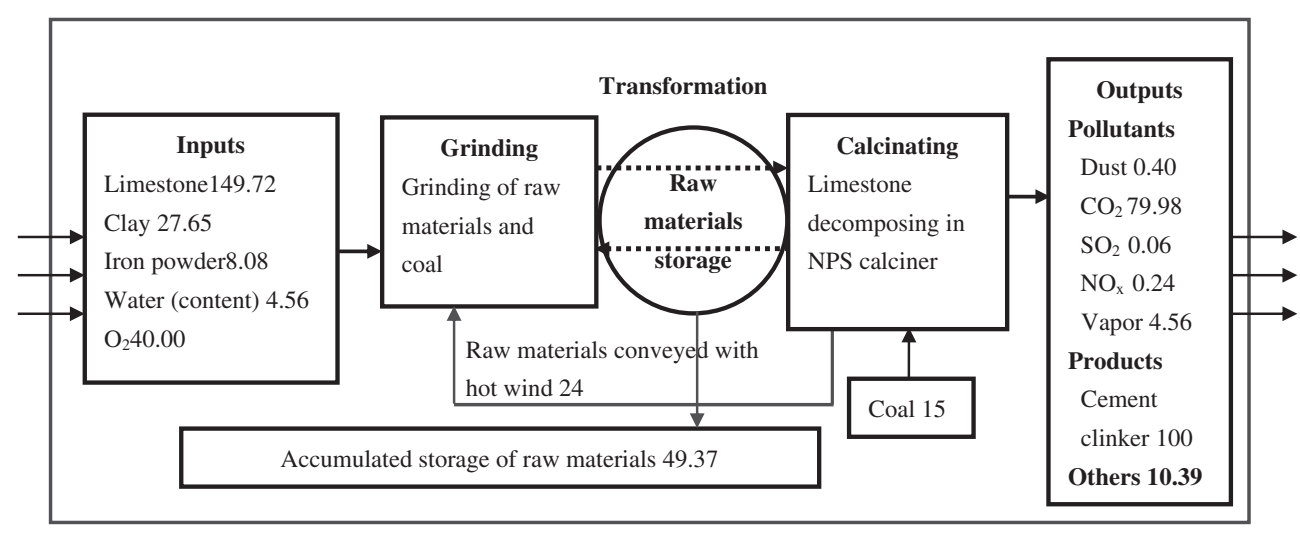

Fig. 6. Metabolic balance diagram in "continuous baking and grinding” phase for NPS kiln (unit: tons/h). 


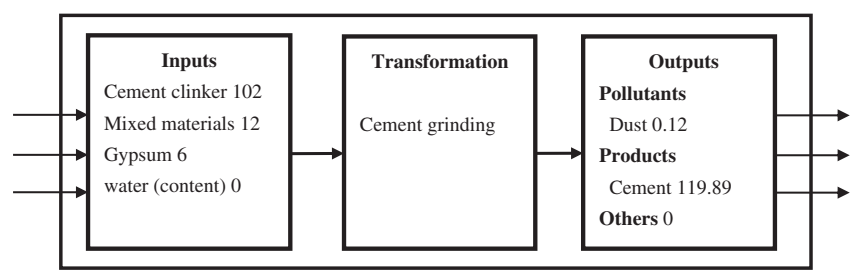

Fig. 7. Metabolic balance diagram in the cement milling phase for NPS kiln (unit: tons/h).

Dust and noise are the main environmental emissions in this phase as well; however, a full set of highly efficient dust collection and elimination equipment enables dust emissions to be strictly controlled, accounting for only $0.1 \%$ of the total, which is much lower than the percentage for the shaft kiln (see Fig. 7). Noise is another variable that differs greatly between the two plants. While workers must generally wear hearing protection in the finish mill or the raw grinding phase of the shaft kiln, NSP kilns are usually so quiet that workers do not hear any noise unless they are right next to the equipment.

\section{Comparative analysis of energy and material metabolisms in cement production systems}

\subsection{Energy and material metabolic efficiency in different phases for the two types of production kilns}

Based on the analysis of the material flow balance in the different phases of the two cement production kilns in Section 3 and the energy consumption data from the cement enterprises investigated, we analyzed the efficiency of raw material usage, energy flows, and environmental emissions in different phases for the two types of kilns. The indicators adopted in this analysis are specified in Section 2.4, and the calculated results are presented below.

As shown in Table 2, the metabolism efficiency of material and energy in the different phases for the shaft kiln is significantly different. Electricity is consumed in all three phases, while heat is only consumed in the calcinating phase for clinker. The minimum of $E_{u e}$ and pollutant emissions $\left(D_{d t}\right)$ as well as the highest value of $M_{u t}$ was found to occur in the raw material preparation phase. In contrast, the calcinating phase of clinker has the minimum $M_{u t}$ and the highest level of emissions (including dust, $\mathrm{SO}_{2}, \mathrm{CO}_{2}$, and $\mathrm{NO}_{\mathrm{X}}$ ). The cement-milling phase also consumes relatively large amounts of materials with the highest electricity input. Dust was produced throughout the production process, whereas other pollutant emissions, including $\mathrm{CO}_{2}$, were only emitted in the calcination for clinker phase.

In the NSP kiln production system (see Table 3), electricity is consumed in both phases. The cement-milling phase has a lower indicator $E_{u e}$ value and uses no heat; in contrast, not only is more electricity consumed in the "continuous baking and grinding" phase, but also heat energy is required. Compared with the cement-milling phase, nearly all pollutant emissions appeared in the first phase of the NSP kiln production system. Pollutant emissions for the NSP kiln were far lower than those for the shaft kiln. The emissions per unit of output fell by $12.5 \%$ for $\mathrm{CO}_{2}, 44.5 \%$ for $\mathrm{NO}_{\mathrm{x}}, 72.5 \%$ for $\mathrm{SO}_{2}$ and $86.2 \%$ for dust. As for energy input, $E_{u e}$ and $E_{u h}$ dropped $4.7 \%$ and $29.5 \%$, respectively. $M_{u t}$ was lower in the "continuous baking and grinding" phase for the NSP kiln than in the corresponding previous two phases for the shaft kiln.

\subsection{The metabolism efficiency of material and energy at a plant level}

Material and energy metabolism at an enterprise level refers to metabolic activities for the overall production system, without focusing on partial activities of each procedural phase. The indicators for analysis are calculated and presented in Tables 4 and 5.

At the enterprise level, a higher value of the indicator $M_{u d}$ was found for the NSP kiln than for the shaft kiln due to a larger amount of direct material input of clay and iron per unit cement product in the NSP kiln, as seen in the analysis of the material flow balance in the different phases in Section 3. However, the $M_{u t}$ indicator for the NSP kiln was lower, indicating a smaller amount of total material inputs per unit cement product. As for energy consumption, nearly no difference was found in $E_{u e}$ for the two procedural lines. Electricity consumption in the NSP kiln does not have a clear advantage, as large blower systems are used in the suspension preheaters and the compressed air cannons used to dislodge raw meal buildups, and in the light of the considerable energetic requirements of the kiln rotation motors and cooling pumps. Total energy consumption for the NSP kiln system was lower than that for the shaft kiln system, as were the pollutant emissions per unit of cement product (for the $D_{d t}, D_{s d}, D_{n x}$, and $D_{c d}$ indictors).

\section{Discussion of the results}

The detailed survey of two typical cement enterprises and the results of the metabolic analysis of the cement production processes at the enterprise level and at the level of different procedural phases presented above indicate that alternate procedures for cement production have a large effect on the type and quantity of input and output and the metabolic behaviors of material and energy flows, and influence metabolism efficiency and corresponding pollutant emissions.

At the enterprise level, the $M_{u d}$ value for the NSP kiln reaches 2.17 tons/ton, which is larger than the value for the shaft kiln (1.58 tons/ton). However, the shaft kiln procedure requires more material input per unit of cement product and has a larger $M_{u t}$ value than the NSP kiln due to a higher level of implicit flows in the shaft kiln production processes. That is to say, the inputs of water, air (other than $\mathrm{O}_{2}$ ), and coal per unit of cement product in the shaft kiln production system are larger than those in the NSP kiln production system by 8.9 times, $38.7 \%$ and $11.9 \%$, respectively. In addition, the total energy consumption per unit of cement product for the shaft kiln is larger than that for the NSP kiln by $38.3 \%$; at the same time, the value of $E_{u \text { e }}$ for the shaft kiln is greater than the value for the NSP kiln by $5.6 \%$. The differences mentioned above indicate a far higher

Table 2

Energy and material metabolic efficiency in the different phases for shaft kiln.

\begin{tabular}{|c|c|c|c|}
\hline Indicators for analysis & Raw meal preparation & Calcination for clinker & Cement milling \\
\hline Total input of materials per unit of intermediate or final product $\left(M_{u t}\right.$, ton/ton) & 99.64 & 49.19 & 99.44 \\
\hline Electricity consumption per unit of output $\left(E_{u e}, \mathrm{~kW} \mathrm{~h} / \mathrm{ton}\right)$ & 21.17 & 27.45 & 37.46 \\
\hline Heat consumption per unit of output $\left(E_{u h}, \mathrm{MJ} / \mathrm{ton}\right)$ & - & 4604.6 & - \\
\hline Dust emissions per unit of output $\left(D_{d t}, \mathrm{~kg} / \mathrm{ton}\right)$ & 3.60 & 27.17 & 5.42 \\
\hline $\mathrm{SO}_{2}$ emissions per unit of output ( $\left.D_{s d}, \mathrm{~kg} / \mathrm{ton}\right)$ & - & 2.18 & - \\
\hline $\mathrm{NO}_{\mathrm{X}}$ emissions per unit of output $\left(D_{n x}, \mathrm{~kg} / \mathrm{ton}\right)$ & - & 4.37 & - \\
\hline $\mathrm{CO}_{2}$ emissions per unit of output $\left(D_{c d}, \mathrm{~kg} / \mathrm{ton}\right)$ & - & 914.42 & - \\
\hline
\end{tabular}

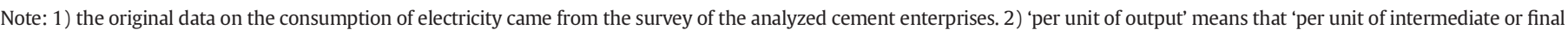
products'. 
Table 3

Energy and material metabolic efficiency in the different phases for NPS kiln.

\begin{tabular}{|c|c|c|}
\hline Indicators & Continuous baking and grinding & Cement milling \\
\hline Total input of materials per unit of intermediate or final product $\left(M_{u}\right.$, ton/ton) & 41.59 & 99.90 \\
\hline Electricity consumption per unit of outputs ( $\left.E_{u e}, \mathrm{~kW} \mathrm{~h} / \mathrm{ton}\right)$ & 46.49 & 35.58 \\
\hline Heat consumption per unit of output ( $E_{u h}, \mathrm{MJ} /$ ton $)$ & 3244.2 & - \\
\hline Dust emissions per unit of outputs ( $\left.D_{c d}, \mathrm{~kg} / \mathrm{ton}\right)$ & 4.03 & 0.96 \\
\hline $\mathrm{SO}_{2}$ emissions per unit of outputs ( $\left.D_{\mathrm{sd}}, \mathrm{kg} / \mathrm{ton}\right)$ & 0.60 & - \\
\hline $\mathrm{NO}_{\mathrm{X}}$ emissions per unit of outputs $\left(D_{n x}, \mathrm{~kg} / \mathrm{ton}\right)$ & 2.38 & - \\
\hline $\mathrm{CO}_{2}$ emissions per unit of outputs $\left(D_{c d}, \mathrm{~kg} / \mathrm{ton}\right)$ & 799.82 & - \\
\hline
\end{tabular}

efficiency of material and energy flows for the NSP kiln than for the shaft kiln due to technological improvements in the use of materials and energy.

With regard to environmental emissions, the $\mathrm{CO}_{2}$ emissions in the calcination for clinker phase stem entirely from the decomposition of raw calcic materials and coal combustion. $\mathrm{CO}_{2}$ emissions for the former are nearly the same in both procedures, namely $503.19 \mathrm{~kg} /$ ton for the shaft kiln and $510.10 \mathrm{~kg} /$ ton for the NSP kiln. Meanwhile, $\mathrm{CO}_{2}$ emissions from the coal combustion process differed markedly between the shaft kiln and the NSP kiln, which amounted to $411.2 \mathrm{~kg} /$ ton and $289.7 \mathrm{~kg} /$ ton, respectively. Total $\mathrm{CO}_{2}$ emissions for the NSP kiln were thus relatively reduced, amounting to $84.8 \%$ of the emissions for the shaft kiln. The $\mathrm{SO}_{2}$ and $\mathrm{NO}_{x}$ emissions also stemmed from coal combustion in the calcination for clinker phase. $\mathrm{SO}_{2}$ emissions for the shaft kiln were 2.78 times greater than those for the NSP kiln, while $\mathrm{NO}_{\mathrm{X}}$ emissions for the shaft kiln were $90.5 \%$ greater than those for the NSP kiln. Dust emissions originated in all of the processes of the different procedural phases, including material breaking, grinding, handling, transporting, as well as drying processes, particularly in the calcination for clinker phase. Furthermore, dust emissions for the shaft kiln were 6.9 times greater than those for the NSP kiln. Clearly, the metabolic efficiency of the NSP kiln is higher and the technology production processes are more environmentally friendly.

Using SimaPro software, we conducted an LCA analysis of the two different production techniques by building process assessment models, and found obvious differences both in the total environmental impact and in single categories. In Figs. 8 and 9, an Eco-indicator 99(H) with Europe EI 99H/H method was adopted to weight various impact categories. Most parameters come from the investigation data and the pollutant emission inventory of Chinese construction materials (SEPA, 1996); missing parameters were obtained from the libraries of BUWAL250, ETH-ESU 96 Unit process (Frishknecht and Jungbluth, 2007; Spriensma, 2004). The results are as follows: Comparing 1 ton of shaft kiln-produced cement with 1 ton of NSP kiln-produced cement, the former amounts to 38.08 Pt., which is 1.7 times as much as NSP kiln cement. With regard to human health, ecosystem quality, and resources, shaft kiln cement is $72 \%, 87 \%$, and $68 \%$ higher than the NSP kiln, respectively. More detailed categories are presented in Fig. 9.

\section{Table 4}

Energy and material metabolic efficiency for the shaft kiln system at enterprise level.

\begin{tabular}{lc}
\hline Indicators (at the level of 1 ton of products) & $\begin{array}{l}\text { The calculated } \\
\text { value }\end{array}$ \\
\hline Direct material input per unit of cement product $\left(M_{u d}\right.$, ton/ton $)$ & 1.58 \\
Total material input per unit of cement product $\left(M_{u t}\right.$, ton/ton $)$ & 3.28 \\
Electricity consumption per unit of cement product $\left(E_{u,}, \mathrm{~kW} \mathrm{~h} / \mathrm{ton}\right)$ & 95 \\
Total energy consumption per unit of cement product $\left(E_{u t}, \mathrm{GJ} / \mathrm{ton}\right)$ & 4.26 \\
$\mathrm{CO}_{2}$ emissions per unit of product $\left(D_{c d}\right.$, ton/ton $)$ & 0.79 \\
Dust emissions per unit of product $\left(D_{d t}, \mathrm{~kg} / \mathrm{ton}\right)$ & 34.05 \\
$\mathrm{SO}_{2}$ emissions per unit of product $\left(D_{s d}, \mathrm{~kg} / \mathrm{ton}\right)$ & 1.89 \\
$\mathrm{NO}_{\mathrm{x}}$ emissions per unit of product $\left(D_{n x}, \mathrm{~kg} / \mathrm{ton}\right)$ & 3.79
\end{tabular}

Note: 1 ) the total input of materials includes inputs of direct materials and the implicit flows. The total energy consumption includes electricity and heat consumption; 2) the data of energy consumption came from the survey of the analyzed enterprises.
Among the various environmental impacts, fossil fuels, respiratory inorganics, and climate change are the largest categories for both the shaft kiln and the NSP kiln. Since the impacts of the respiratory organics, radiation, and ozone layer only account for a tiny portion, these were not included in Fig. 9. As is shown, each category of the shaft kiln is higher than that of the NSP kiln, which indicates that from an LCA perspective, the production processes of the shaft kiln have a larger environmental impact than those of the NSP kiln.

\section{Conclusions}

Although the use of the NSP kiln surged from 14\% to $89 \%$ from 2000 to 2011 in China, the shaft kiln has still been adopted by a number of small plants in certain economically undeveloped areas for financial reasons (CMIIT, 2011). The attention that the plant operators pay on market demands greatly exceeds the technological potential for pollution reduction and resource saving. On the other hand, differences in raw material quality, calcination technology, the clinker ratio of cement, potential emission factors, and the oxidation rates of various fuels resulting in the real situation may have significant differences compared with those estimations based on WBCSD/CSI (2009b). In this study, we analyzed the metabolic flow characteristics of materials and energy and compared the differences in metabolic efficiency and pollutant emissions for the two representative procedures, the shaft kiln and the NSP kiln, based on a field survey and data collection from two typical cement enterprises in China.

The analysis presented above indicates that the performance of the NSP kiln procedure is superior to that of the shaft kiln in different phases and at different scales. The results also demonstrate the cement production processes to have a decisive impact on resource consumption and pollution emissions. During the period of process upgrading and industrial restructuring in the Chinese cement production industry, efforts to shut down outdated production facilities should be increased. We should focus on reducing the input of raw materials and energy consumption, improving use efficiency, and minimizing negative impacts on environmental health throughout the cement production process so as to build a healthier and circular (recycling) cement production system in China's cement industry.

Table 5

Energy and material metabolic efficiency in the NPS kiln system at enterprise level.

\begin{tabular}{lc}
\hline Indicators (at the level of 1 ton of products) & $\begin{array}{l}\text { The calculated } \\
\text { value }\end{array}$ \\
\hline Direct material inputs per unit of cement product $\left(M_{u d}\right.$, ton/ton $)$ & 2.17 \\
Total material inputs per unit of cement product $\left(M_{u t}\right.$, ton $/$ ton $)$ & 2.83 \\
Electricity consumption per unit of cement product $\left(E_{u e}, \mathrm{~kW} \mathrm{h/ton}\right)$ & 90 \\
Total energy consumption per unit of cement product $\left(E_{u t}, \mathrm{GJ} / \mathrm{ton}\right)$ & 3.08 \\
$\mathrm{CO}_{2}$ emissions per unit of product $\left(D_{c d}\right.$, ton/ton $)$ & 0.67 \\
Dust emissions per unit of product $\left(D_{d t}, \mathrm{~kg} / \mathrm{ton}\right)$ & 4.32 \\
$\mathrm{SO}_{2}$ emissions per unit of product $\left(D_{s d}, \mathrm{~kg} / \mathrm{ton}\right)$ & 0.50 \\
$\mathrm{NO}_{\mathrm{x}}$ emissions per unit of product $\left(D_{n x}, \mathrm{~kg} / \mathrm{ton}\right)$ & 1.99
\end{tabular}

Note: 1) the total input of materials includes direct input of materials and the implicit flows. The total energy consumption includes electricity and heat consumption; 2) the data of energy consumption came from a survey of the analyzed enterprises. 


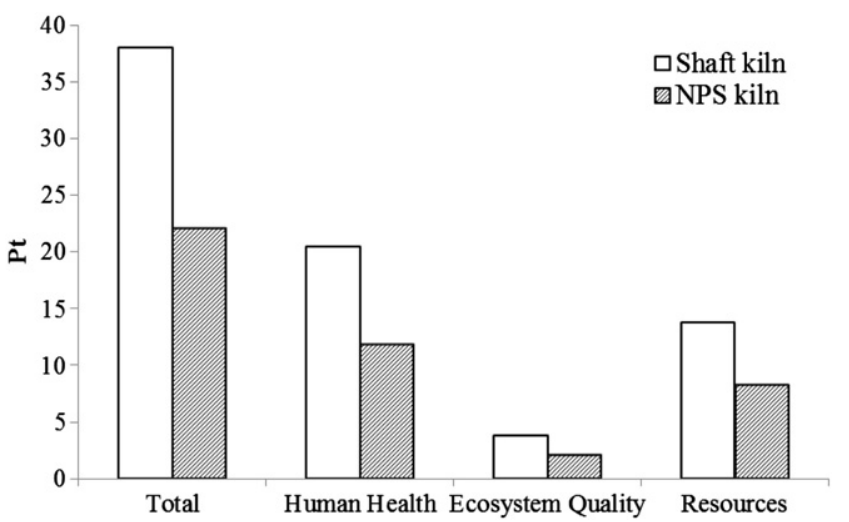

Fig. 8. Comparing 1-ton shaft kiln produced cement with 1-ton NPS kiln produced cement (method: Eco-indicator 99(H) V2.06/Europe EI 99H/H weighting).

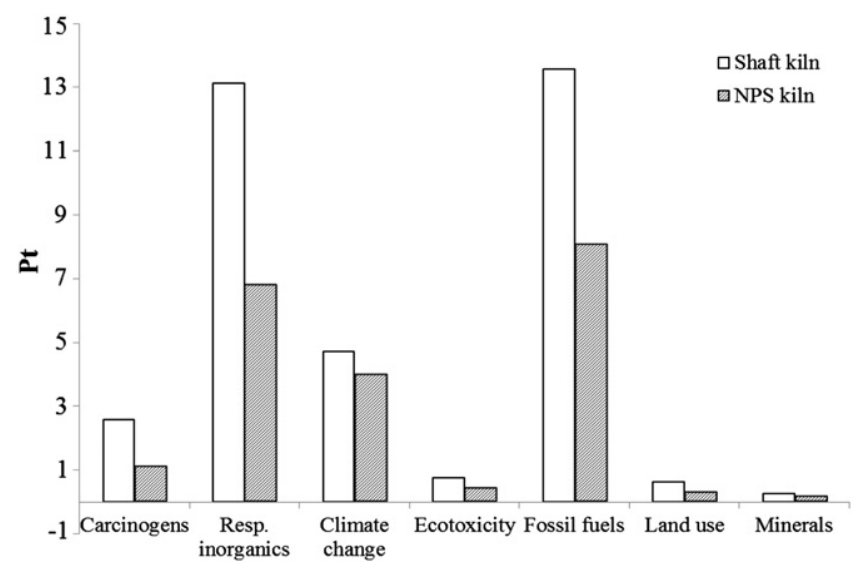

Fig. 9. Comparing 1-ton shaft kiln produced cement with 1-ton NPS kiln produced cement (per impact category).

\section{Acknowledgments}

This research was supported by the National Natural Science Foundation of China (41171442, 70873121) and the State Key Laboratory of Urban \& Regional Ecology (SKLURE 2012-1-01).

\section{References}

Aïtcin, P.C., 2000. Cements of yesterday and today: concrete of tomorrow. Cem. Concr. Res. 30, 1349-1359.

Ayres, R.U., 1989. Industrial metabolism. Technol. Environ. 1989, 23-49.

Baumann, H., Tillman, A.M., 2004. The Hitch Hiker's Guide to LCA. An Orientation in Life Cycle Assessment Methodology and Application. Studentlitteratur AB, (External organization).

Bergsdal, H., Brattebo, H., Bohne, R.A., Mueller, D.B., 2007. Dynamic material flow analysis for Norway's dwelling stock. Build. Res. Inf. 35, 557-570.

Brunner, P.H., 2012. Substance flow analysis. J. Ind. Ecol. 16, 293-295.

Burbidge, J.L., 1963. Production flow analysis. Prod. Eng. 42, 742-752.

CMIIT (Chinese Ministry of Industry and Information Technology), 2011. Operation Status of Major Industry Sectors in 2010. Material Industry, (http://www.miit.gov.cn/ n11293472/n11295125/n11299605/13578992.html).

Erkman, S., 1997. Industrial ecology: an historical view. J. Clean. Prod. 5, 1-10.

Fischer-Kowalski, M., Hüttler, W., 1998. Society's metabolism. J. Ind. Ecol. 2, 107-136.

Forkes, J., 2007. Nitrogen balance for the urban food metabolism of Toronto, Canada. Resour. Conserv. Recycl. 52, 74-94.
Frishknecht, R, Jungbluth, N. 2007. SimaPro 7 Database Manual: The ETH-ESU 96 Libraries. Pre Consultants \& ESU Services, (http://www.pre.nl/download/manuals/ DatabaseManualETH-ESU96.pdf25).

Frosch, R.A., 1992. Industrial ecology: a philosophical introduction. Proc. Natl. Acad. Sci. 89, 800-803.

Frosch, R.A., Gallopoulos, N.E., 1989. Strategies for manufacturing. Sci. Am. 261, 144-152.

Gerst, M.D., Graedel, T.E., 2008. In-use stocks of metals: status and implications. Environ. Sci. Technol. 42, 7038-7045.

Graedel, T., Allenby, B., 2003. Industrial ecology. 1995. Prentice Hall, Englewood Cliffs, New Jersey 7632, 83-187.

Guo, X.Y., Zhong, J.Y., Song, Y., Tian, Q.H., 2010. Substance flow analysis of zinc in China. Resour. Conserv. Recycl. 54, 171-177.

Jorgenson, A.K., Rice, J., 2005. Structural dynamics of international trade and material consumption: a cross-national study of the ecological footprints of less-developed countries. J. World-Syst. Res. 11, 57-77.

Kleijn, R., Huele, R., van der Voet, E., 2000. Dynamic substance flow analysis: the delaying mechanism of stocks, with the case of PVC in Sweden. Ecol. Econ. 32, 241-254.

Lei, Y., Zhang, Q., Nielsen, C., He, K., 2011. An inventory of primary air pollutants and $\mathrm{CO}_{2}$ emissions from cement production in China, 1990-2020. Atmos. Environ. 45, 147-154.

Li, Y.T., Zhang, Y., Li, S.S., 2009. Measurement and evaluation of the material metabolism capability in typical Chinese cities. Bio-Inspired Computing, 2009. BIC-TA '09. Fourth International Conference on IEEE, pp. 1-9.

Ma, B.G., Li, X.G., Wang, X.G., 2005. Study on environmental loading and the control measures in cement industry. Cem. Eng. 2, 79-82 (in Chinese).

Madlool, N., Saidur, R., Hossain, M., Rahim, N., 2011. A critical review on energy use and savings in the cement industries. Renew. Sust. Energ. Rev. 15, 2042-2060.

Mansson, N., Bergback, B., Sorme, L., 2009. Phasing out cadmium, lead, and mercury. J. Ind. Ecol. 13, 94-111.

McMillan, C.A., Moore, M.R., Keoleian, G.A., Bulkley, J.W., 2010. Quantifying US aluminum in-use stocks and their relationship with economic output. Ecol. Econ. 69, 2606-2613.

Michaelis, P., Jackson, T., 2000. Material and energy flow through the UK iron and steel sector. Part 1: 1954-1994. Resour. Conserv. Recycl. 29, 131-156.

Ortiz, O., Castells, F., Sonnemann, G., 2009. Sustainability in the construction industry: a review of recent developments based on LCA. Constr. Build. Mater. 23, 28-39.

Salazar, K., McNutt, M.K., 2011. Mineral Commodity Summaries. US Geological Survey, Reston, Virginia.

Schneider, M., Romer, M., Tschudin, M., Bolio, H., 2011. Sustainable cement productionpresent and future. Cem. Concr. Res. 41, 642-650.

SEPA (State Environmental Protection Administration), 1996. Manual of Chinese Industrial Pollutants and Emission Factors. China Environmental Science Press, Beijing.

Spatari, S., Bertram, M., Gordon, R.B., Henderson, K., Graedel, T., 2005. Twentieth century copper stocks and flows in North America: a dynamic analysis. Ecol. Econ. 54, 37-51.

Spriensma, R., 2004. SimaPro Database Manual: The BUWAL 250 library. PRe Consultants, Amersfoort.

Stigliani, W.M., Jaffe, P.R., Anderberg, S., 1993. Heavy metal pollution in the Rhine basin. Environ. Sci. Technol. 27, 786-793.

Sui, T., 2009. China's cement industry towards sustainability. Report in Italcementi Group (http://www.italcementigroup.com/ENG/Sustainable+Development/Best+pratices/ Sui+Tongbo_Energy.htm).

Udo de Haes, H.A., van der Voet, E., Kleijn, R., 1997. Substance flow analysis (SFA), an analytical tool for integrated chain management. In: Bringezu, S., Fischer-Kowalski, M., Kleijn, R., Palm, V. (Eds.), Regional and National Material Flow Accounting: From Paradigm to Practice of Sustainability, pp. 32-42.

Ulgiati, S., Odum, H., Bastianoni, S., 1994. Emergy use, environmental loading and sustainability an emergy analysis of Italy. Ecol. Model. 73, 215-268.

WBCSD/CSI (World Business Council for Sustainable Development/Cement Sustainability Initiative), 2009a. Cement Industry Energy and $\mathrm{CO}_{2}$ Performance. "Getting the Numbers Right"WBCSD/CSI.

WBCSD/CSI (World Business Council for Sustainable Development/Cement Sustainability Initiative), 2009b. Global cement database on $\mathrm{CO}_{2}$ and energy information. http:// www.wbcsdcement.org/GNRv2/geo/GNR-Indicator_3212-geo.html. http://www. wbcsdcement.org/GNRv2/geo/GNR-Indicator_338-geo_Europe-allyear.html.

Wiedmann, T., Minx, J., 2007. A definition of 'carbon footprint'. Ecol. Econ. Res. Trends 2, 55-65.

Wiedmann, T., Lenzen, M., Turner, K., Barrett, J., 2007. Examining the global environmental impact of regional consumption activities-part 2: review of input-output models for the assessment of environmental impacts embodied in trade. Ecol. Econ. 61, $15-26$.

Wolman, A., 1965. The metabolism of cities. Sci. Am. 213, 179-190.

$\mathrm{Xu}$, J.H., Fleiter, T., Eichhammer, W., Fan, Y., 2012. Energy consumption and $\mathrm{CO}_{2}$ emissions in China's cement industry: a perspective from LMDI decomposition analysis. Energ Policy 50, 821-832.

Yang, Q., Guo, S., Yuan, W.H., Shen, Q., Chen, Y.Q., Wang, X.H., Wu, T.H., Chen, Z.M., Alsaedi, A., Hayat, T., 2015. Energy-dominated carbon metabolism: a case study of Hubei province, China. Ecol. Inform. 26, 85-92. 